Klinik für Kronen- und Brückenprothetik, Teilprothetik und zahnärztliche Materialkunde

Direktor: Prof. Dr. med. dent. Christoph Hämmerle

\title{
Effect of clinical and laboratory contamination media on the adhesion of luting cement to direct and indirect resin composite materials
}

\author{
INAUGURAL-DISSERTATION \\ zur Erlangung der Doktorwürde der Zahnmedizin \\ der Medizinischen Fakultät \\ der Universität Zürich
}

vorgelegt von

Bilgin Koç-Dündar

Genehmigt auf Antrag von Prof. Dr. med. dent. Christoph Hämmerle Zürich 2016 


\section{Publikationshinweis}

Effect of clinical and laboratory contamination media on the adhesion of luting cement to direct and indirect resin composite materials

Publiziert am: $\quad 07.11 .2016$

Journal: Im Journal of Adhesion Science and Technology, [Epub].

http://www.tandfonline.com/doi/full/10.1080/01694243.2016.1250 492 


\section{Publikation}




\title{
Effect of clinical and laboratory contamination media on the adhesion of luting cement to direct and indirect resin composite materials
}

\author{
Bilgin Koc-Dundar and Mutlu Özcan
}

Dental Materials Unit, Center for Dental and Oral Medicine, Clinic for Fixed and Removable Prosthodontics and Dental Materials Science, University of Zurich, Zurich, Switzerland

\begin{abstract}
This study evaluated the effect of contamination media on the adhesion of resin cement to resin composites. Specimens of direct (DRC) (Quadrant Photo Posterior) and indirect resin composite (IRC) (Gradia) $(N=300, n=15$ per group) were prepared. Except the control group (C), the specimens of DRC and IRC were contaminated with one of the following media: (a) saliva (S), (b) silicon (SI), (c) dental stone (D), and (d) isolation medium (I). While one half was only rinsed with water, the other half was silica coated (30 $\mu \mathrm{m} \mathrm{SiO}{ }_{2}$, Siljet). All specimens were silanized (Monobond Plus) and coated with adhesive resin (Heliobond). Resin cement (Variolink II) was bonded to the substrates and photo-polymerized for $40 \mathrm{~s}$. After thermocycling (x5.000, 5-55 $\left.{ }^{\circ} \mathrm{C}\right)$, composite-cement interface was loaded under shear in a Universal Testing Machine ( $1 \mathrm{~mm} / \mathrm{min})$. Data (MPa) were analyzed using Univariate analysis, Tukey's and Dunnett-T3 tests. Both contamination media $(p=0.000)$ and surface conditioning $(p=$ 0.005 ) significantly affected adhesion to DRC and IRC. No significant difference was found between the DRC and IRC (without: $p=0.098$; with: $p=0.084)$. Significantly lower results were obtained after SI (DRC: $0.66 \pm 0.6$; IRC: $0.8 \pm 1.3$ ) followed by I contamination (DRC: $2.1 \pm$ 2.6; IRC: $0.8 \pm 1.3)(p<0.05)$. Regardless of contamination medium, surface conditioning significantly increased the results for both DRC (15.1 $\pm 6.1-23.6 \pm 3.7)$ and IRC $(20.3 \pm 5.4-25.1 \pm 3.6)(p<0.05)$. Weibull distribution increased after surface conditioning for both DRC (without: 1.33-3.27; with: 2.55-9.34) and IRC (without: 1.07-3.75; with: 3.7-7.73). Predominantly adhesive (132 out of 150) failures were observed when surfaces were not conditioned.
\end{abstract}

\section{ARTICLE HISTORY}

Received 15 August 2016

Revised 28 October 2016

Accepted 14 October 2016

\section{KEYWORDS}

Adhesion; adhesive cementation; contamination; direct resin composite; indirect resin composite; surface conditioning

\section{Introduction}

Photo-polymerized resin composites are commonly used restorative materials in minimal invasive dentistry for both anterior and posterior restorations. Such tooth-colored restorations can adhere to the dental tissues using adhesive materials, and they can be made directly or indirectly at chairside or at the dental laboratory. One shortcoming of direct application 
of resin composites is the polymerization shrinkage that influences the stress produced at the interface between the dental tissues, leading to marginal gaps or hypersensitivity when the stress exceeds the bond strength between the resin composite and the tooth.[1] On the contrary, resin composite restorations made using indirect techniques result in less polymerization shrinkage, water sorption and, therefore, discoloration.[1] Moreover, indirect resin composites (IRCs) require less finishing and polishing time at chairside compared to direct resin composites (DRC). Both DRCs and IRCs could be processed as an indirect restoration material especially for large restorations when direct manipulation is difficult to achieve intraorally. Indirect techniques, when employed at the dental laboratory, do not require high technical skills since occlusal anatomy and proximal contacts can be established by the dental technician.[2-4]

IRC materials are usually classified according to the size of their inorganic particles; hybrid IRCs contain particles greater than $1 \mu \mathrm{m}$, microhybrid IRCs have particles smaller than $1 \mu \mathrm{m}$, and nano-hybrid IRCs have particles smaller than $0.4 \mu \mathrm{m}$.[2] The increase in the size and the volume of inorganic particles improves their resistance to wear, decreases the polymerization contraction, and also increases the glaze and polishability.[3-6] The degree of conversion has a significant influence on the physical and biological properties of resin composite restorations. [2,5,6] IRCs present higher conversion, as polymerization is carried out in the laboratory or at chairside in special photo-polymerization units in which all surfaces of the restoration can be polymerized.[6] Depending on the type of the polymerization unit, combination of light, heat, vacuum, and pressure result in an improvement from 10 to $20 \%$ in the mechanical properties of these materials as opposed to the direct polymerization techniques. [6]

For durable adhesive cementation, contamination has to be avoided since adhesion of resin-based materials to a clean substrate is the principal prerequisite for all adhesive procedures. [7] The second step after conditioning is the application of a silane coupling agent that creates the chemical bond between the organic and inorganic materials connecting with its hydrophilic part to the silica atoms of the glass phase and interacting through the hydrophobic part with the methacrylate groups of the resin polymer.[8] These two steps of surface conditioning are crucial for the adhesion of resin cement to DRC and IRC restorations, regardless of the resin cement used.[9-12]

When DCRs or IRCs are fabricated on a plaster model indirectly, by the dental technician at the laboratory or by the clinician, there exist possible scenarios of contamination of the composite surface. One possible contamination medium is with the dental stone as a result of incomplete separation of the restoration from the plaster model, during try-in of the restoration on the plaster model or through storage in the dental lab or transport. In some situations, dental stone is isolated with an isolation medium that eventually also contaminates the intaglio surfaces of the restoration. Similarly, prior to try in, the cement gap is controlled with a layer of silicone materials to control the fit of the restoration and during try-in, unintentional contact of the restoration with saliva in the mouth could all contaminate the surface. Contamination effect on adhesion of resin cements to ceramics has been investigated previously.[13-21] Such events may have deleterious impact on the resin-ceramic adhesion [13-15] and cleaning after contamination of the etched ceramic surfaces was proposed to be mandatory prior to silanization.[17-21] 
A number of cleansing regimens have been suggested in the literature for the contaminated ceramic surfaces. While rinsing with water spray only does not result in durable adhesion,[21] the most frequently studied cleaning methods in the literature to remove saliva contamination were airborne particle abrasion with $50 \mu \mathrm{m} \mathrm{Al}_{2} \mathrm{O}_{3}$ particles, phosphoric acid, ethanol, acetone, or isopropanol.[15-20] Even though airborne particle abrasion is often described to be the best method to clean zirconia after saliva contamination,[15-17,22] it has detrimental effects on lithium disilicate ceramic.[15] There is limited information available where mainly phosphoric acid was studied as a cleaning medium and suggested for removing saliva contamination from lithium disilicate surfaces. $[14,15]$ Also, controversial information is available as to whether phosphoric acid creates antagonist effect on the adhesion of resin-based materials on ceramics.[22,23] Hence, cleansing protocol for ceramic materials has not been established yet. Additionally, information on similar effects on resin-based materials are scarce.[24] On the other hand, the best adhesion protocol for resin composites requires initial surface conditioning with air-abrasion using alumina particles coated with silica followed by silanization.[25-27] Thus, it could be anticipated that air-abrasion protocol could remove the contaminated layer and circumvent the decrease in bond strength of the resin cement to the conditioned surface.

The objectives of this study therefore are to evaluate the effect of different contamination media that could be encountered during fabrication and cementation in clinical procedures on the adhesion of resin cement to direct and indirect resin composites. The hypotheses tested were that (a) different contamination media would not significantly affect the bond strength and (b) surface conditioning with silica coating and silanization would restore adhesion after contamination.

\section{Materials and methods}

The brands, types, manufacturers, and chemical compositions of the materials used in this study are listed in Table 1.

\section{Specimen preparation}

Specimens of direct (DRC) (Quadrant Photo Posterior, Cavex, Haarlem, The Netherlands) and indirect resin composite (IRC) (Gradia, GC, Tokyo, Japan) (diameter: $5 \mathrm{~mm}$; height: $4 \mathrm{~mm} ; N=300, n=15$ per group) were prepared in polymethylmethacrylate (Scandiquick, Scandia, Hagen, Germany) cavities, keeping the upper surface free for bonding purposes. Specimens for DRC were photo-polymerized for $60 \mathrm{~s}$ using LED polymerization device (Bluephase G2, Ivoclar Vivadent, Schaan, Liechtenstein). The light output was verified to be above $1200 \mathrm{mw} / \mathrm{cm}^{2}$ after every 15 specimens using a radiometer radiometer (CureRite, Dentsply-Caulk, Milford, USA). IRC specimens were polymerized in the laboratory polymerization device (Heraflash, HiLite power, Hereaus Kulzer, Hanau, Germany) for $60 \mathrm{~s}$. All specimens were ground flat using 1200-grit silicone carbide paper (WS Flex18C, Hermes, Hamburg, Germany) under water-cooling and ultrasonically cleaned (Vitasonic, VITA Zahnfabrik, Bad Säckingen, Germany) for $5 \mathrm{~min}$ in distilled water to remove the residue, dried with oil-free compressed air. 
Table 1. The brands, types, chemical compositions, and manufacturers and of the main materials used in this study.

\begin{tabular}{|c|c|c|c|}
\hline Brand & Type & Chemical composition & Manufacturer \\
\hline Monobond Plus & Silane coupling agent & $\begin{array}{l}\text { Ethanol, 3-trimethoxysilsylpropyl- } \\
\text { metha-crylate, methacrylated phosphoric } \\
\text { acid ester }\end{array}$ & $\begin{array}{l}\text { Ivoclar Vivadent, Schaan, } \\
\text { Liechtenstein }\end{array}$ \\
\hline Heliobond & Adhesive resin & $\begin{array}{l}\text { bis-GMA, dimethacrylate, initiators and } \\
\text { stabilizers }\end{array}$ & Ivoclar Vivadent \\
\hline Variolink II & $\begin{array}{l}\text { Dual-polymerized } \\
\text { resin cement }\end{array}$ & $\begin{array}{l}\text { bis-GMA, UDMA, TEGDMA, BPO, CQ, barium } \\
\text { glass, ytterbium trifluoride, Ba-Al fluoros- } \\
\text { ilicate glass, spheroid mixed oxide } \\
\text { Particle size: } 0.04-3 \mu \mathrm{m} \text { (mean: } 0.7 \mu \mathrm{m} \text { ), } \\
\text { Filler load (base: } 73.4 \text { wt\%) } \\
\text { Filler load (catalyst high viscosity: } 77.2 \text { wt\%) }\end{array}$ & Ivoclar Vivadent \\
\hline $\begin{array}{l}\text { Quadrant Photo } \\
\text { Posterior }\end{array}$ & $\begin{array}{l}\text { Photo-polymerized } \\
\text { hybrid composite }\end{array}$ & $\begin{array}{l}\text { Poly-functional methacrylate-based mono- } \\
\text { mers; bis-GMA, UDMA, TEGDMA, Barium } \\
\text { aluminium silicate glass fillers }(0.7-5 \mu \mathrm{m}) \text {, } \\
\text { porous } \mathrm{SiO}_{2}(8 \mu \mathrm{m}), \text { polymerization } \\
\text { catalysts, inorganic pigments }\end{array}$ & $\begin{array}{l}\text { Cavex, Haarlem, The } \\
\text { Netherlands }\end{array}$ \\
\hline Gradia & $\begin{array}{l}\text { Photo-polymerized } \\
\text { micro-hybrid } \\
\text { composite system }\end{array}$ & UDMA, Ethyleneglycol dimethacrylate & GC, Tokyo, Japan \\
\hline Fuji Rock & Dental stone & Type 4 & GC \\
\hline Optosil & $\begin{array}{l}\text { C-Silicone precision } \\
\text { impression material }\end{array}$ & $\begin{array}{l}\text { Mixture of sodium borosilicate and amor- } \\
\text { phous silica }\end{array}$ & $\begin{array}{l}\text { Heraeus Kulzer, Hanau, } \\
\text { Germany }\end{array}$ \\
\hline Iso-K & Isolation medium & Petroleum jelly & $\begin{array}{l}\text { Candulor, Glattpark, } \\
\text { Switzerland }\end{array}$ \\
\hline Siljet & Air abrasion particles & $\mathrm{Al}_{2} \mathrm{O}_{3}, \mathrm{SiO}_{2}$ & $\begin{array}{l}\text { Danville Engineering, San } \\
\text { Ramon, CA, USA }\end{array}$ \\
\hline
\end{tabular}

While half of the specimens of DRC and IRC were not contaminated and acted as control groups $(\mathrm{C})$, the other half were randomly divided into four groups and contaminated as follows.

\section{Contamination methods}

Saliva (S): Saliva was collected from one person (B.K.) who refrained from eating and drinking $2 \mathrm{~h}$ before collection.[21,26] Saliva was rubbed on the human dentin disks in a custom-made device within the vicinity of $5 \mathrm{~mm}$ along $x$-axis for 5 times while loaded under $500 \mathrm{~g}$. Then, it was left undisturbed for $60 \mathrm{~s}$. Subsequently, dentin disks were removed and composite specimens were rinsed with water spray for $15 \mathrm{~s}$ and air-dried for $10 \mathrm{~s}$.

Dental stone (D): For the dental stone contamination, disks were prepared from Type 4 dental stone (Fuji Rock, GC, Tokyo, Japan), ground dry with silicone carbide paper of 240grit. The dental stone disks with dental stone powder were placed on the ceramic specimens and surfaces were contaminated in a similar manner as described for saliva contamination using the same custom-made device. After $60 \mathrm{~s}$ of contamination, dental stone disks were removed and composite specimens were rinsed with water spray for $15 \mathrm{~s}$ and air-dried for $10 \mathrm{~s}$.

Silicone (S): In this group, C-silicon precision impression material (Optosil, Heraeus Kulzer, Hanau, Germany) was mixed according to the manufacturer's instructions and placed in a $(5 \times 5 \mathrm{~mm})$ glass mold. After setting, the upper surface of the silicone material brought in contact with the resin composite specimen surfaces contaminated in a similar manner as described for saliva contamination using the same custom-made device. After 
$60 \mathrm{~s}$ of contamination, silicone material was removed and composite specimens were rinsed with water spray for $15 \mathrm{~s}$ and air-dried for $10 \mathrm{~s}$.

Isolation medium (I): In this group, two coats of isolation medium (Iso-K, Candulor, Glattpark, Switzerland), used for dental stone, were applied on the composite surfaces, airthinned, left undisturbed for $60 \mathrm{~s}$, and then rinsed with water spray for $15 \mathrm{~s}$ and air-dried for $10 \mathrm{~s}$.

Distribution of experimental groups based on the contamination media and resin composite materials as substrates are presented in Figure 1.

\section{Surface conditioning}

The specimens were air-abraded with $30 \mu \mathrm{m}$ aluminum oxide particles coated with silica (Siljet, Danville Engineering, San Ramon, CA, USA) at 2.8 bar pressure from a distance of approximately $10 \mathrm{~mm}$ from the surface, in a circular motion for $5 \mathrm{~s}$ using an intraoral air-abrasion device (Dento-Prep, RØNVIG, Daugaard, Denmark).

\section{Cementation procedure}

After surface conditioning and drying the surface with oil-free air, all specimens were coated with one layer of silane coupling agent (Monobond Plus) using a micro-brush and left to react for $60 \mathrm{~s}$. Then one layer of adhesive resin (Heliobond, Ivoclar Vivadent) was applied with a micro brush for $40 \mathrm{~s}$, gently air-thinned with oil-free air but not photo-polymerized. Translucent polyethylene molds (height: $4 \mathrm{~mm}$, diameter: $3 \mathrm{~mm}$ ) were stabilized on the composite specimens in a custom-made device. Base and catalyst paste of dual polymerized resin cement (Variolink II, Ivoclar Vivadent) were mixed in a 1:1 ratio on a mixing pad for $10 \mathrm{~s}$. The mold was filled with the resin cement, a metal was inserted to ensure $100 \mu \mathrm{m}$ cement thickness at the first layer of cement and it was photo-polymerized using an LED unit (Bluephase G2, Ivoclar Vivadent; light intensity: $1200 \mathrm{~W} / \mathrm{cm}^{2}$ ) for $40 \mathrm{~s}$ from five directions (top, mesial, distal, buccal, lingual) from a distance of $2 \mathrm{~mm}$.

After bonding procedures, the specimens were stored in an incubator (Binder $\mathrm{GmbH}$, Tuttlingen, Germany) at $37^{\circ} \mathrm{C}$ in the dark for $24 \mathrm{~h}$ and then subjected to thermocycling for 5.000 times $\left(5-55^{\circ} \mathrm{C}\right.$, dwell time: $30 \mathrm{~s}$, transfer time from one bath to the other: $5 \mathrm{~s}$ ) (Haake DC 10, Thermo Haake, Karlsruhe, Germany).

\section{Testing procedure and failure analysis}

Specimens were mounted in the jig of the Universal Testing Machine (Zwick/Roell Z010, Ulm, Germany) and force was applied using a shearing blade with a 45-degree inclination to the composite-luting cement interface until failure occurred. The load was applied to the adhesive interface, as close as possible to the surface of the substrate at a crosshead speed of $1 \mathrm{~mm} / \mathrm{min}$ and the stress-strain curve was analyzed with the corresponding software program.

Following bond strength tests, substrate surfaces of all specimens were inspected under optical stereomicroscope (Zeiss, Göttingen, Germany) at $\times 10$ magnification. After evaluating all images, failure types were defined as 'adhesive' with no resin cement left on the composite (Score 0), 'mixed' where less than half of the cement was left on the composite 


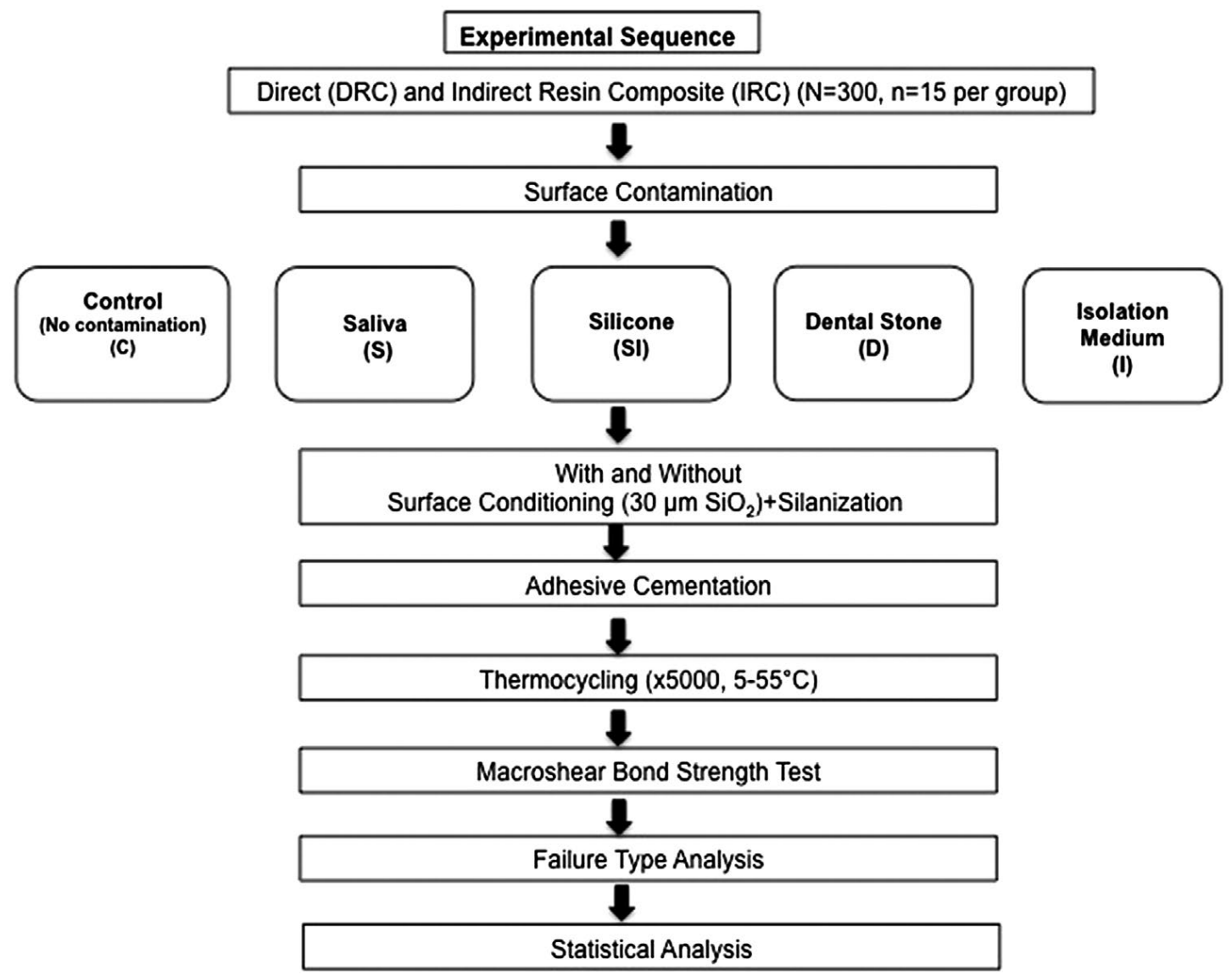

Figure 1. Allocation of experimental groups based on the direct and indirect resin composite materials and contamination methods.

surface with no cohesive failure of the substrate (Score 1), and 'cohesive' failure in the substrate composite (Score 2).

\section{Statistical analysis}

According to the two-group Satterthwaite t-test (SPSS Software V.20, Chicago, IL, USA) with a 0.05 two-sided significance level, a sample size of 15 in each experimental group was calculated to provide more than $80 \%$ power to detect a difference of $8 \mathrm{MPa}$ between mean values. Kolmogorov-Smirnov and Shapiro-Wilk tests were used to test normal distribution of the data. As the data were normally distributed, a three-way analysis of variance (ANOVA) was applied to analyze possible differences between the groups where the bond strength was the dependent variable and contamination media (4 levels: dental stone, saliva, silicone, isolation medium) and resin composite (2 levels: direct versus indirect) as independent variables. Interaction of contamination media and cleansing regimens were analyzed using Tukey's and Dunnett-T3 post hoc tests. Maximum likelihood estimation without a correction factor was used for a two-parameter Weibull distribution to interpret predictability and reliability of adhesion (Minitab Software V.16, State College, PA, USA). $P$ values less than 0.05 were considered to be statistically significant in all tests. 


\section{Results}

Both contamination media $(p=0.000)$ and surface conditioning $(p=0.005)$ significantly affected the adhesion to DRC and IRC. Interaction terms were significant $(p=0.009)$ (Dunnett-T3).

Overall, no significant difference was found between the DRC and IRC (without: $p=0.098$, with: $p=0.084$ ). Among non-surface conditioned groups, significantly lower results were obtained after SI contamination (DRC: $0.66 \pm 0.6$; IRC: $0.8 \pm 1.3$ ) followed by I contamination (DRC: $2.1 \pm 2.6$; IRC: $0.8 \pm 1.3)(p<0.05)$ compared to those of other contamination media (DRC: $6.7 \pm 2.3-14.7 \pm 5.1$; IRC: $4.8 \pm 3.1-12.7 \pm 7.3$ ) (Tables $2 a$ and $2 b)$.

Regardless of contamination medium, surface conditioning significantly increased the results for both DRC $(15.1 \pm 6.1-23.6 \pm 3.7)$ and IRC $(20.3 \pm 5.4-25.1 \pm 3.6)(p<0.05)$. Surface conditioning also significantly increased the bond strength in $\mathrm{C}$ groups of DRC (without: $6.7 \pm 2.3$; with: $21.4 \pm 4.3$ ) and IRC (without: $4.8 \pm 3.1$; with: $25.1 \pm 3.6)(p<0.05)$.

Weibull distribution increased after surface conditioning for both DRC (without: 1.333.27; with: 2.55-9.34) and IRC (without: 1.07-3.75; with: 3.7-7.73) but even after conditioning lower shape values were observed for D-DRC (2.55) and SI-IRC (3.7) groups.

In all experimental groups, surface conditioning increased the bond strength results from 37 to $96 \%$ (Figure 2(a) and (b)).

Predominantly adhesive (132 out of 150) failures were observed in all groups when surfaces were not conditioned. After conditioning adhesive failures (34 out of 150) decreased and cohesive failures (100 out of 150) increased.

\section{Discussion}

Durable adhesion of resin composite restorations is crucial especially in minimal invasive applications. Thus, this study was undertaken to study the effect of different contamination media that could be encountered during fabrication and cementation in clinical procedures on the adhesion of resin cement to direct and indirect resin composites. Based on the results obtained, since contamination type significantly affected the results the first hypothesis could be rejected. On the other hand, surface conditioning significantly increases the bond results after contamination yielding to the acceptance of the second hypothesis.

Different test methods (i.e. macroshear, microshear, macrotensile, and microtensile tests) are available for testing adhesion of resin-based materials to dental materials. In order to measure the bond strength values between an adherent and a substrate accurately, it is crucial that the bonding interface should be the most stressed region, regardless of the test methodology employed.[28] Although homogeneous stress distribution is expected at the adhesive joint with microtensile tests, during specimen preparations, more frequent pretest failures are experienced.[28] Hence, shear tests are still considered more practical to screen the performance of adhesive procedures. Also, in an attempt to compare the results obtained with those of previous studies, in this study shear test was employed.

Although different processing methods have been employed for DRC and IRC, overall both materials showed nonsignificant mean bond strength results after contamination with and without surface conditioning. In fact, both DRC and IRC were methacrylate based where the latter was polymerized in a laboratory polymerization device. The number of 
Table 2a. The mean shear bond strength values (MPa \pm standard deviations), confidence intervals (95\%) between resin cement and direct and indirect resin composite after different contamination media without surface conditioning, Weibull parameters (shape and scale), distribution and frequency of failure types per experimental group analyzed after bond strength test: Adhesive: no resin cement left on the composite surface; Mixed: less than half of the cement left adhered on the composite surface with no cohesive failure of the substrate.

\begin{tabular}{|c|c|c|c|c|c|c|c|c|c|}
\hline \multirow[b]{2}{*}{ Group } & \multirow{2}{*}{$\begin{array}{c}\text { Resin } \\
\text { composite }\end{array}$} & \multirow{2}{*}{$\begin{array}{l}\text { Surface con- } \\
\text { ditioning }\end{array}$} & \multirow{2}{*}{$\begin{array}{l}\text { Contam- } \\
\text { ination } \\
\text { medium }\end{array}$} & \multirow{2}{*}{$\begin{array}{c}\text { Shear bond } \\
\text { strength } \\
\text { (Mean } \pm \text { SD) (Cl } \\
95 \%)\end{array}$} & \multicolumn{2}{|c|}{$\begin{array}{l}\text { Weibull } \\
\text { parameters }\end{array}$} & \multicolumn{3}{|c|}{ Failure type distribution $n(\%)$} \\
\hline & & & & & Shape & Scale & Adhesive & Mixed & Cohesive \\
\hline 1 & DRC & No & C & $\begin{array}{l}6.7 \pm 2.3^{\mathrm{a}} \\
(4.63-8.9)\end{array}$ & 3.15 & 7.52 & $15(100)$ & $0(0)$ & $0(0)$ \\
\hline 2 & DRC & No & $S$ & $\begin{array}{c}9.4 \pm 7.2^{\mathrm{a}} \\
(7.38-11.5)\end{array}$ & 1.33 & 10.3 & $13(87)$ & $0(0)$ & $2(13)$ \\
\hline 3 & DRC & No & SI & $\begin{array}{c}0.66 \pm 0.6^{\mathrm{b}} \\
(-1.41-2.72)\end{array}$ & 2.93 & 1.11 & $15(100)$ & $0(0)$ & $0(0)$ \\
\hline 4 & DRC & No & D & $\begin{array}{c}14.7 \pm 5.1^{c} \\
(12.66-16.78)\end{array}$ & 3.27 & 16.27 & $0(0)$ & $13(87)$ & $2(13)$ \\
\hline 5 & DRC & No & I & $\begin{array}{c}2.1 \pm 2.6^{b} \\
(0.03-4.16)\end{array}$ & 1.19 & 2.6 & $15(100)$ & $0(0)$ & $0(0)$ \\
\hline 6 & IRC & No & C & $\begin{array}{c}4.8 \pm 3.1^{\mathrm{b}} \\
(2.81-6.94)\end{array}$ & 1.73 & 5.51 & $15(100)$ & $0(0)$ & $0(0)$ \\
\hline 7 & IRC & No & $S$ & $\begin{array}{c}10.8 \pm 3.3^{c} \\
(8.77-12.89)\end{array}$ & 3.75 & 12.07 & $15(100)$ & $0(0)$ & $0(0)$ \\
\hline 8 & IRC & No & SI & $\begin{array}{c}0.8 \pm 1.3^{b} \\
(-1.29-2.83)\end{array}$ & 1.19 & 1.31 & $15(100)$ & $0(0)$ & $0(0)$ \\
\hline 9 & IRC & No & D & $\begin{array}{c}12.7 \pm 7.3^{c} \\
(18.27-22.4)\end{array}$ & 1.51 & 13.89 & $14(93)$ & $0(0)$ & $1(7)$ \\
\hline 10 & IRC & No & I & $\begin{array}{c}2.3 \pm 3.1^{\mathrm{b}} \\
(0.249-4.38)\end{array}$ & 1.07 & 2.8 & $15(100)$ & $0(0)$ & $0(0)$ \\
\hline
\end{tabular}

The same superscript lowercase letters in the same column indicate no significant differences $(p<0.05)$. *For group descriptions see Figure 1.

stroboscopi xenon lamps, in a mirrored circular chamber and the presence of vacuum in the chamber could affect the physical properties and degree of conversion of IRCs. Apparently, the lack of vacuum and the duration of polymerization $(60 \mathrm{~s})$ did not affect the degree of conversion compared to DRC material that was polymerized using an LED polymerization device for the same duration.[5,6] Longer duration of polymerization ranging from 4 to 15 min influenced degree of conversion of IRCs other than tested in this study.

In this study, two clinical and two laboratory contamination scenarios were simulated. All contamination media affected the bond results at varying levels. For both DRC and IRC when conditioning was not performed, from laboratory contamination methods dental stone showed higher results than those of other contamination methods. It could be anticipated that the dental stone powder acted as microretentive surfaces elements on the composite materials. After surface conditioning, either lower or non-significant difference was observed in this group compared to other groups. Air-particle abrasion possibly removed this layer but not effectively coated the surface with silica to further react with silane coupling agent. Other laboratory contamination method was isolation medium. With both DRC and IRC, this medium presented one of the most intensive contamination effect. Although in the nonconditioned groups, the contaminated surfaces were only washed with distilled water, evidently after rinsing this layer was not completely removed leaving no sites for reaction with the methacrylate groups of the resin cement. Typically, such separating materials contain petroleum jelly with high surface wettability.[29] 
Table $2 \mathrm{~b}$. The mean shear bond strength values ( $\mathrm{MPa} \pm$ standard deviations), confidence intervals (95\%) between resin cement and direct and indirect resin composite after different contamination medium with surface conditioning, Weibull parameters (shape and scale), distribution and frequency of failure types per experimental group analyzed after bond strength test: Adhesive: no resin cement left on the composite surface; Mixed: less than half of the cement left adhered on the composite surface with no cohesive failure of the substrate.

\begin{tabular}{|c|c|c|c|c|c|c|c|c|c|}
\hline \multirow[b]{2}{*}{ Group } & \multirow{2}{*}{$\begin{array}{c}\text { Resin } \\
\text { composite }\end{array}$} & \multirow{2}{*}{$\begin{array}{l}\text { Surface con- } \\
\text { ditioning }\end{array}$} & \multirow{2}{*}{$\begin{array}{l}\text { Contam- } \\
\text { ination } \\
\text { medium }\end{array}$} & \multirow{2}{*}{$\begin{array}{l}\text { Shear bond } \\
\text { strength } \\
\text { (Mean } \pm \mathrm{SD}) \\
(\mathrm{Cl} 95 \%)\end{array}$} & \multicolumn{2}{|c|}{$\begin{array}{c}\text { Weibull } \\
\text { parameters }\end{array}$} & \multicolumn{3}{|c|}{ Failure type distribution $n(\%)$} \\
\hline & & & & & Shape & Scale & Adhesive & Mixed & Cohesive \\
\hline 1 & DRC & Yes & C & $\begin{array}{c}21.4 \pm 4.3^{\mathrm{a}} \\
(18.88-23.94)\end{array}$ & 5.85 & 23.09 & $0(0)$ & $2(13)$ & $13(87)$ \\
\hline 2 & DRC & Yes & $S$ & $\begin{array}{c}16.1 \pm 2.0^{\mathrm{b}} \\
(13.62-18.51)\end{array}$ & 9.34 & 16.95 & $5(33)$ & $0(0)$ & $10(67)$ \\
\hline 3 & DRC & Yes & SI & $\begin{array}{c}16.2 \pm 2.8^{\mathrm{b}} \\
(13.77-18.66)\end{array}$ & 7.45 & 17.35 & $5(33)$ & $1(7)$ & $9(60)$ \\
\hline 4 & DRC & Yes & D & $\begin{array}{c}15.1 \pm 6.1^{b} \\
(12.65-17.54)\end{array}$ & 2.55 & 16.78 & $0(0)$ & $2(13)$ & $13(87)$ \\
\hline 5 & DRC & Yes & 1 & $\begin{array}{c}23.6 \pm 3.7^{\mathrm{a}} \\
(21.49-26.37)\end{array}$ & 6.72 & 25.21 & $1(7)$ & $1(7)$ & $13(86)$ \\
\hline 6 & IRC & Yes & C & $\begin{array}{l}25.1 \pm 3.6^{a} \\
(22.7-27.6)\end{array}$ & 7.73 & 26.73 & 7 (46) & $1(7)$ & $7(46)$ \\
\hline 7 & IRC & Yes & $S$ & $\begin{array}{c}21 \pm 5.2^{\mathrm{a}} \\
(18.56-23.5)\end{array}$ & 4.52 & 22.99 & $6(42)$ & $2(14)$ & $7(46)$ \\
\hline 8 & IRC & Yes & SI & $\begin{array}{c}22.3 \pm 7^{\mathrm{a}} \\
(19.9-24.78)\end{array}$ & 3.7 & 24.81 & $4(28)$ & $3(21)$ & $8(56)$ \\
\hline 9 & IRC & Yes & D & $\begin{array}{l}20.3 \pm 5.4^{\mathrm{a}} \\
(17.9-22.8)\end{array}$ & 5.01 & 22.11 & $5(35)$ & $3(21)$ & $7(46)$ \\
\hline 10 & IRC & Yes & 1 & $\begin{array}{c}23.6 \pm 3.7^{a} \\
(21.16-26.04)\end{array}$ & 6.72 & 25.21 & $1(7)$ & 1 (7) & $13(86)$ \\
\hline
\end{tabular}

The same superscript lowercase letters in the same column indicate no significant differences $(p<0.05)$. *For group descriptions see Figure 1.

(a)

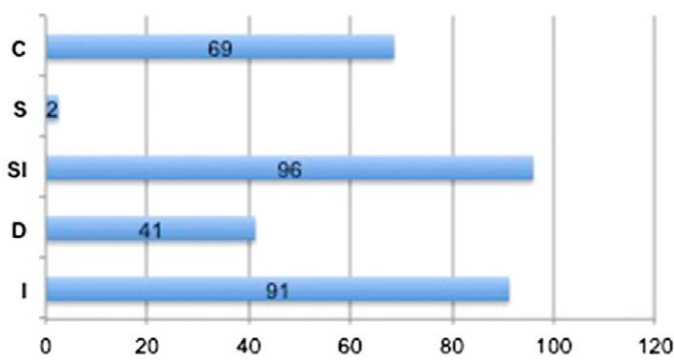

(b)

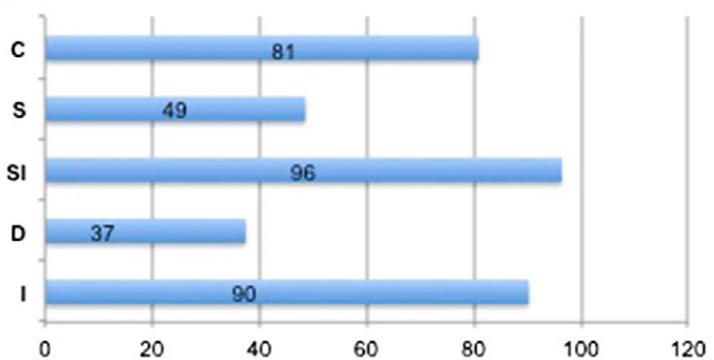

Figure 2. (a-d) Bond strength change in percentage after surface conditioning for (a) direct and (b) indirect resin composite groups contaminated with different medium. *For group descriptions see Figure 1.

From clinical perspective, saliva and silicone are the most relevant contamination media. Saliva contains organic materials such as salivary proteins, enzymatic molecules, bacteria and food debris, and inorganic compounds such as mineral ions in water.[30] Adhesion of salivary proteins to dental materials and tooth surfaces result in the formation of acquired enamel pellicle that is free of bacteria at a thickness of 10-20 nm within a few minutes. [31] With an increase in the protein transmission from saliva, the thickness of this protein layer reaches to 100-1000 $\mathrm{nm}$ between 30 and $90 \mathrm{~min}$.[31] The resulting persistent protein 
contamination from saliva in particular was shown to hinder adhesion of the resin cements to restorative materials.[14,22] Since it is almost inevitable to avoid the saliva contamination of restorations during the try-in procedure of especially minimal invasive reconstructions, prior to adhesive cementation, the contaminants should be removed in order to achieve durable adhesion.[32]

In previous studies, water spray, alcohol, and acetone seem not be effective in removing saliva residues from glass ceramics $[14,22,23]$ but $35-37 \%$ phosphoric acid gel application presented effective cleaning. [14] The mechanism of phosphoric acid is not completely understood but it is postulated that the acid possibly penetrates the salivary film and etches the porcelain surface underneath, thereby releasing the salivary film from the surface.[14] Phosphoric acid also removes the adsorbed proteins by coagulation or desorption from ceramic surface onto the cleaning particles. [32] Subsequent water rinsing can then remove the coagulated or desorbed proteins. On the contrary, phosphoric acid was reported to passivate the zirconia surface when used in combination with phosphate methacrylate-based primers used in adhesive cementation. [32,33] In several other studies, cleaning pastes with zirconia particles were demonstrated to remove saliva contaminants from both glass- and oxide-based ceramic surfaces but it was not effective in removing silicone residues. $[15,16]$ The efficacy of cleansing protocols is dictated by the media, duration and mechanical and chemical interactions in the case of using slurry.

In this study, in order not to prolong the clinical workflow, additional procedures or combined cleansing regimens were not practiced. One important finding of this study was the beneficial effect of surface conditioning and silanization on the adhesion result. Regardless of the contamination media bond strength results could be restored when the DRC or IRC surfaces were air-abraded with silica coating and subsequently silanized. The increased reliability of adhesion was also verified in all groups when Weibull moduli were considered.

The bond strength results should be coupled with failure type analysis. The increased incidence of cohesive failures in the substrate clearly indicates that adhesion achieved exceeded the cohesive strength of the DRC and IRC.

Silica coating surface conditioning was followed by the application of silane coupling agent. The poly-condensation of bifunctional silane monomer with the general formula of ( $\mathrm{R}-\mathrm{O}-$ ) 3-Si-O-R, R being the first and $\mathrm{O}-\mathrm{R}$ the second silane functionality can provide a highly cross-linked and reactive poly-organosiloxane layer to composites.[34] Nevertheless, hydrolysis of silane in water diminishes lifetime of adhesive joints. [35,36] Solvent evaporation represents a factor affecting the coupling potential of silanes. [37] Even though a small amount of solvent may help silane wetting, incomplete evaporation may impair adhesion. Water, alcohol, acetone, acetic acid, and other byproducts that remain in the pores of the network, if not completely expelled by drying procedure, may remain as hydrogen bonded to the $\mathrm{OH}$-rich silica fillers of the composite substrate. This may decrease the number of bond sites available for reacting with silane, thus compromising the final degree of siloxane bond formation.[37] Accordingly, heat treatment process was suggested to evaporate the solvent and volatile byproducts from the silane reaction, catalyzing and completing the condensation reactions both with the substrate and within the silane coating.[37] In this study, hydrolytic aging was practiced in a thermocyle device for 5000 times but no heat treatment was applied to the silane layer in any of the groups that could be considered as a limitation of this study. 
The majority of clinical studies using fiber reinforced IRCs presented a survival rate of $\geq 72 \%$ after $2-5$ years when bonded to retentive cavities. [38] On the other hand, survival rate of ISFRCR in previous studies with other fibers and resin cements and veneering composites ranged between $93 \%$ up to 1 year in 31 patients [39] and $93.5-100 \%$ up to 58 months in 135 patients. [40] In none of these studies, clinical protocols were mentioned prior to adhesion protocols. Thus, future clinical studies should report whether contamination was experienced prior to adhesive cementation and what kind of the cleansing protocols was employed for resin composite materials in case of a failure.

\section{Conclusions}

From this study, the following could be concluded:

(1) Contamination of direct and indirect resin composite with saliva, silicone, dental stone, or isolation medium impaired the adhesion of resin cement significantly.

(2) Surface conditioning with silica coating and silanization could restore adhesion after all contamination medium tested for both direct and indirect resin composites.

(3) Weibull analysis showed less reliable adhesion after dental stone and silicone contamination even after surface conditioning for direct and indirect resin composites, respectively.

(4) Failure types were predominantly adhesive when substrate surfaces were not conditioned but after surface conditioning the incidence of cohesive failures increased in all groups.

\section{Clinical relevance}

Contamination of cementation surfaces of direct and indirect resin composite with saliva, silicone, dental stone, or isolation medium impairs the adhesion of resin cement but chairside silica coating and silanization could restore the adhesion.

\section{Conflict of interest}

The authors did not have any commercial interest in any of the materials used in this study.

\section{Acknowledgements}

The authors acknowledge Mr A. Trottmann, University of Zürich, Center for Dental and Oral Medicine, Zürich, Switzerland, for his assistance with the specimen preparation and Cavex, Haarlem, The Netherlands and GC, Tokyo, Japan for generous provision of the composite materials.

\section{References}

[1] Hickel R, Manhart J. Longevity of restorations in posterior teeth and reasons for failure. J Adhes Dent. 2001;3:45-64. 
[2] Kildal KK, Ruyter IE. How different curing methods affect mechanical properties of composites for inlays when tested in dry and wet conditions. Eur J Oral Sci. 1997;105:353-361.

[3] Özcan M, Alander P, Vallittu PK, et al. Effect of three surface conditioning methods to improve bond strength of particulate filler resin composites. J Mater Sci Mater Med. 2005;16:21-27.

[4] Touati B, Aidan N. Second generation laboratory composite resins for indirect restorations. J Esthet Dent. 1997;9:108-118.

[5] Souza RO, Özcan M, Mesquita AM, et al. Effect of different polymerization devices on the degree of conversion and the physical properties of an indirect resin composite. Acta Odontol Latinoam. 2010;23:129-135.

[6] Souza RO, Özcan M, Michida SM, et al. Conversion degree of indirect resin composites and effect of thermocycling on their physical properties. J Prosthodont. 2010;19:218-225.

[7] Plueddemann EP. Silane coupling agents. New York, NY: Plenum Press; 1991.

[8] Matinlinna JP, Lassila LV, Özcan M, et al. An introduction to silanes and their clinical applications in dentistry. Int J Prosthodont. 2004;17:155-164.

[9] Nagai T, Kawamoto Y, Kakehashi Y, et al. Adhesive bonding of a lithium disilicate ceramic material with resin-based luting agents. J Oral Rehabil. 2005;32:598-605.

[10] Pisani-Proenca J, Erhardt MC, Valandro LF, et al. Influence of ceramic surface conditioning and resin cements on microtensile bond strenght to a glass ceramic. J Prosthet Dent. 2006;96: 412-417.

[11] Lu YC, Tseng H, Shih YH, et al. Effects of surface treatments on bond strenght of glass-infiltrated ceramic. J Oral Rehabil. 2001;28:805-813.

[12] Zortuk M, Kilic K, Gurbulak AG, et al. Tensile bond strength of a lithium-disilicate pressed glass ceramic to dentin of different surface treatments. Dent Mater J. 2010;29:418-424.

[13] Swift B, Walls AW, McCabe JF. Porcelain veneers: the effect of contaminants and cleaning regimens on the bond strength of porcelain to composite. Br Dent J. 1995;179:203-208.

[14] Aboush YE. Removing saliva contamination from porcelaine veneers before bonding. J Prosthet Dent. 1998;80:649-653.

[15] Yang B, Scharnberg M, Wolfart S, et al. Influence of contamination on bonding to zirconia ceramic. J Biomed Mater Res B Appl Biomater 2006;81:283-290.

[16] Quaas AC, Yang B, Kern M, et al. 2.0 bonding to contaminated zirconia ceramic after different cleaning procedures. Dent Mater. 2007;23:506-512.

[17] Yang B, Lange-Jansen HC, Scharnberg M, et al. Influence of saliva contamination on zirconia ceramic bonding. Dent Mater. 2008;24:508-513.

[18] Klosa K, Wolfart S, Lehmann F, et al. The effect of storage conditions, contamination modes and cleaning procedures on the resin bond strenght to lithium disilicate ceramic. J Adhes Dent. 2009;11:127-135.

[19] Phark JH, Duarte S Jr, Kahn H, et al. Influence of contamination and cleaning on bond strength to modified circonia. Dent Mater. 2009;25:1541-1550.

[20] Zhang S, Kocjan A, Lehmann F, et al. Influence of contamination on resin bond strenght to nano-structured alumina-coated zirconia ceramic. Eur J Oral Sci. 2010;118:396-403.

[21] Nikolaus F, Wolkewitz M, Hahn P. Bond strenght of composit resion to glass ceramic after saliva contamination. Clin Oral Invest. 2013;17:751-755.

[22] Aladag A, Elter B, Comlekoglu E, et al. Effect of different cleaning regimens on the adhesion of resin to saliva-contaminated ceramics. J Prosthodont. 2015;24:136-145.

[23] Yang B, Wolfart S, Scharnberg M, et al. Influence of contamination on zirconia ceramic bonding. J Dent Res. 2007;86:749-753.

[24] Shimazu K, Karibe H, Ogata K. Effect of artificial saliva contamination on adhesion of dental restorative materials. Dent Mater J. 2014;33:545-550.

[25] Brendeke J, Özcan M. Effect of physicochemical aging conditions on the composite-composite repair bond strength. J Adhes Dent. 2007;9:399-406.

[26] Rinastiti M, Özcan M, Siswomihardjo W, et al. Effects of surface conditioning on repair bond strengths of non-aged and aged microhybrid, nanohybrid, and nanofilled composite resins. Clin Oral Invest. 2011;15:625-633. 
[27] Özcan M, Koc-Dundar B. Composite-composite adhesion in dentistry: a systematic review and meta-analysis. J Adhes Sci Tech. 2014;21:2209-2229.

[28] Della Bona A, van Noort R. Shear vs. tensile bond strength of resin composite bonded to ceramic. J Dent Res. 1995;74:1591-1596.

[29] Kim TH, Ahn TJ, Enciso R, et al. Effect of gypsum separating media on the appearance of stone cast surfaces. J Prosthet Dent. 2014;112:1001-1005.

[30] Lendenmann U, Grogan J, Oppenheim FG. Saliva and dental pellicle - a review. Adv Dent Res. 2000;14:22-28.

[31] Hannig M. Ultrastructural investigation of pellicle morphogenesis at two different intraoral sites during a 24-h period. Clin Oral Invest. 1999;3:88-95.

[32] Bock T, Özcan M. Protocol for removal of clinically relevant contaminants from glass ceramicbased restorations. J Adhes Dent. 2015;17:474-475.

[33] Feitosa SA, Patel D, Borges AL, et al. Effect of cleansing methods on saliva-contaminated zirconia an evaluation of resin bond durability. Oper Dent. 2014;40:163-171.

[34] Matinlinna JP, Lassila LV, Özcan M, et al. An introduction to silanes and their clinical applications in dentistry. Int J Prosthodont. 2004;17:155-164.

[35] Ishida H, Koenig JL. Effect of hydrolysis and drying on the siloxane bonds of a silane coupling agent deposited on E-glass fibers. J Polym Sci B Polym Phys. 1980;18:233-237.

[36] Barghi N. To silanate or not to silanate: making a clinical decision. Compend Cont Educ Dent. 2000;21:659-662.

[37] Queiroz JR, Benetti P, Özcan M, et al. Surface characterization of feldspathic ceramic using ATR FT-IR and ellipsometry after various silanization protocols. Dent Mater. 2012;28:189-196.

[38] van Heumen CCM, Kreulen CM, Creugers NHJ. Clinical studies of fiber-reinforced resinbonded fixed partial dentures: a systematic review. Eur J Oral Sci. 2009;117:1-6.

[39] Vallittu PK, Sevelius C. Resin-bonded, glass fiber-reinforced composite fixed partial dentures: a clinical study. J Prosthet Dent. 2000;84:413-418.

[40] Kumbuloglu O, Özcan M. Clinical survival of indirect, anterior 3-unit surface-retained fibrereinforced composite fixed dental prosthesis: up to 7.5-years follow-up. J Dent. 2015;43:656-663. 